\title{
VIVIR DE MILAGRO EN MILAGROS: REFLEXIONES PARA EL TRABAJO SOCIAL ${ }^{3}$
}

\section{Milagros Colón Castillo}

La palabra cáncer genera sentimientos de temor, incertidumbre y profunda tristeza. Solamente quien lo ha vivido sabe a conciencia que esta condición nos remueve el piso debajo de nuestros pies y nos expone a una vida de zozobra. Este libro recoge la experiencia de la autora con el cáncer, desde diversas perspectivas tales como las relaciones con la pareja y los hijos(as) la muerte, los hospitales, las amistades, la oración, el dinero y el sistema de servicios de salud. Por medio de ensayos redactados en noches de insomnio, nos conduce a diferentes vivencias de dolor, amor y aprendizaje. Sin abandonar su sentido del humor, nos narra situaciones que estremecen la más íntima de las fibras.

Sin poder desligarse de su profesión como trabajadora social, la autora ofrece al final de cada ensayo, sus reflexiones para sus colegas y estudiantes de esta disciplina. Su objetivo, que la lectura del libro nos convenza de que el cáncer puede ser el inicio de una nueva etapa de servicio en nuestras vidas, con mayor sensibilidad y dedicación. Para la profesión, que nos enseñe una nueva manera de sentir empatía y respeto por quienes son objetos de opresión del sistema de salud. En sus propias palabras: Solo deseo que por medio de mi aventura (en la cual me embarqué de manera involuntaria) mis colegas, estudiantes, amigos(as), conocidos(as), personal de salud y pacientes de cáncer encuentren acompañados sus pensamientos y sentimientos; se den permiso para expresarlos y se sientan capaces de pedir ayuda para luego darla a otros y otras.

El libro termina con un análisis crítico que hace la autora del sistema de servicios de salud, tema que ha tratado en diversos

\footnotetext{
${ }^{3}$ San Juan, Puerto Rico, 2014, ISBN 978-1- 61887- 438- 2.

${ }^{4}$ Catedrática Escuela Trabajo Social, Universidad Interamericana de Puerto Rico.
} 
ensayos de su obra. En el mismo, describe la manera en que a su juicio, el mal llamado sistema de salud se perdió en el camino hacia lo que debió ser su meta de lograr la salud óptima de cada puertorriqueño y puertorriqueña. En su lugar se convirtió en un medio más para producirle dinero a las aseguradoras de salud y a los proveedores de servicio.

La autora va detallando cómo en los servicios médicos en general y hospitales en particular, cada paciente deja de ser el centro y razón de ser del sistema y se convierte en presa indefensa de los esfuerzos dirigidos a enriquecer a unos sectores privilegiados a expensas de quienes necesitan y pagan con dolor físico, angustia y hasta la muerte los vaivenes de los proveedores inescrupulosos que se lucran del dolor humano.

La Dra. Colón Castillo hace una propuesta a la clase profesional del trabajo social para combatir el escarnio que cada día cobra la vida de muchos y muchas: la transformación del quehacer profesional a un trabajo social radical. En ese ensayo final enumera los principios de este tipo de trabajo social y las acciones que cada uno de éstos sugiere para la consecución de un pueblo más sano en su cuerpo y su espíritu. La lectura puede ayudar a los(as) trabajadores(as) sociales a reconceptuar verdaderamente su misión y rescatar las funciones que dieron razón de ser al ejercicio de la profesión en los escenarios médicos. Se recalca en el texto que siempre se mantiene como el norte la consecución de la justicia social. 